\title{
Comparative study of tramadol and ketorolac in the pain management of third molar tooth extraction
}

\author{
M.M. Shaik1, J. Kumar ${ }^{2}$, S. Mobina ${ }^{3}$, N. Satyanarayana 4 , P. Sunitha ${ }^{5}$ \\ ${ }^{1}$ Lecturer in pharmacology, ${ }^{2}$ Assistant Professor in Pharmacology, ${ }^{4}$ Lecturer in Anatomy, ${ }^{5}$ Lecturer in Physiology, College of \\ Medical Sciences, Bharatpur, Nepal \\ ${ }^{3} J u n i o r$ Resident, St Joseph's Dental College, Eluru, Andhra Pradesh, India
}

\begin{abstract}
Objective: Clinical comparison of efficacy, duration of action, onset of action, side effects of two most commonly used analgesics tramadol and ketorolac after the third molar tooth extraction.

Materials and methods: The present study was carried out at department of oral surgery, Mamata Dental Hospital, Khammam, India. 150 patients were randomly selected and divided into two groups. Group A received $50 \mathrm{mg}$ of tramadol orally and Group B received $10 \mathrm{mg}$ of ketorolac orally. In both groups dose was repeated for next 24 hrs. Visual scale analog was used for the collection of pain intensity from the patients.
\end{abstract}

Results: In Group A, the analgesia started within 1hour and at the end of 24 hours, pain intensity was 2.12 out of 10 on visual analog scale. In Group B, analgesia started within 30 mins and at the end of 24 hours, the pain intensity was 2.98 on visual analog scale. Sedation associated with dizziness and muscle relaxation was observed with tramadol in 5\% of patients and sweating in $8 \%$ patients. While in case of ketorolac, 33\% of patients suffered with side effects. Among them 33\% patients suffered with bleeding at the site of tooth extraction and $20 \%$ patients suffered with epigastric pain. The analgesic effect of $50 \mathrm{mg}$ tramadol lasted up to 6 hours and that of ketorolac lasted for 5 hour.

Conclusion: The study shows that tramadol is a suitable and safe analgesic for the relief of post-extraction pain and is more effective than ketorolac with prolonged analgesia and minimal side effects.

Key Words: Tramadol, ketorolac, third molar tooth extraction,

\section{Introduction}

The wisdom tooth (or third molar) is usually the last tooth to erupt into the mouth anytime after about 16 years of age. Frequently, there is not enough room

Correspondences: Munvar Miya Shaik

E-mail: munvar.shaik@gmail.com in the mouth to accommodate the erupting wisdom teeth and therefore, they might not always come into the mouth normally. Wisdom teeth are usually either impacted forwards into the tooth in front or backwards into the jaw bone. An impacted wisdom tooth causes infection in the gum surrounding the tooth leading to 
pain and swelling. Sometimes cysts also formed due to impacted wisdom tooth. To avoid these problems it is always better to remove the tooth. however, the management of pain consequent to tooth extraction is always a major concern for the individual..$^{1,2}$

The way pain is experienced is a reflection of the individual's emotional, motivational, cognitive, social, and cultural circumstances. The pain of tooth extraction is likely to be the most severe pain that an individual experiences during his or her life. ${ }^{3}$ Many individuals rate the pain of tooth extraction as very severe or intolerable. The pain of tooth extraction varies among individuals, and each extraction of an individual may be quite different. Management of post-extraction pain relieves suffering and leads to earlier mobilization, shortened hospital stay, reduced hospital costs and increased patient satisfaction. ${ }^{4,5,6}$

Tramadol is an atypical centrally-acting analgesic because of its combined effects as an opioid agonist and a serotonin and noradrenaline reuptake inhibitor. The risk of respiratory depression is significantly lower at equianalgesic doses and does not depress the hypoxic ventilatory response. It has limited effects on gastrointestinal motor function. Nausea and vomiting are the most common side effects and tramadol does not increase seizure incidence when compared to other analgesic agents. Tramadol has been used clinically and evaluated during the past 20 years with broad indications leading to its widespread use. ${ }^{?}$

Ketorolac tromethamine is a member of the pyrrolo-pyrrole group of nonsteroidal antiinflammatory drugs (NSAIDs) which was previously reported for the short term management of moderate to severe pain. The primary molecular basis for antiinflammatory, antipyretic and analgesic effects of
Ketorolac is the inhibition of prostaglandin synthesis by competitive blocking of the enzyme cyclooxygenase (COX).

The present study was conducted keeping in view giving the quicker, prolonged and safer post-extraction analgesic after third molar tooth extraction for quicker recovery of the patient from the post-extraction pain. This study was the clinical comparison of efficacy, safety and patient satisfaction of clinically widely used analgesics, tramadol and ketorolac. There were some reports published the comparing the parenteral tramadol and ketorolac in maxiofacilary surgery. ${ }^{8,9}$

\section{Materials and methods}

One hundread and fifty patients from routine admissions with tooth extraction were selected randomly during the period of 10 months from July 2008 to April 2009 in the department of oral surgery, Mamata Dental Hospital affiliated to Mamata Dental College, Khammam, India. The inclusion criteria were: age in between 18 to 60 , undergoing into third molar tooth extraction, alertness and stability. The exclusion criteria were: history of drug or substance abuse, allergy to opioids or any other contraindication for the use of opioids, end stage renal disease, history of seizure or any abnormal laboratory tests that could interfere with our results.

The methodology and procedure of study had been cleared by the ethical committee and clinical research review committee, Mamata Dental College. All the individuals were well informed about the study, methodology and also about the visual analog scale prior to tooth extraction. The individuals were unawared of the analgesic which they had taken during the study. The drugs ketorolac and tramadol were 
M M Shaik et al. Comparative study of Tramadol and Ketorolac in the pain management of third molar tooth extraction

procured from the hospital pharmacy and they have been assigned a code. Patients were randomly assigned in either treatment groups with an assigned code.

The patients were divided into two groups containing 75 patients in each group. All the codes of administered drugs were disclosed only after the pain assessment. The group 'A' received tramadol 50mg oral dose before the extraction and dose repeated after 6 hours. The group 'B' received ketorolac 10mg oral dose before the extraction and dose was repeated after 6hrs. Pain assessment was done by verbal rating using Visual Analog Scale. ${ }^{10,11}$ [0 - no pain, 2 - mild pain, 4 - tolerable, 6 - distressful pain, 8 - severe pain and 10 - totally disabling pain]. The pain assessment was started after the tooth extraction at time points of $30 \mathrm{~min}, 1,2,3,4,5,6,12,18$ and 24 hrs. The patient's vital signs including heart rate, respiratory rate and blood pressure were recorded at every time point after the assessment of pain intensity. Statistical analyses were performed using Chi-square test.

\section{Results}

The majority of the patients scored an average pain intensity of ' 8.07 ' on visual analog scale as the maximum pain felt by them in their life time. The analgesic effect for group ' $A$ ' who were taken tramadol started within $1^{\text {st }}$ hour and reached the maximum analgesic effect in 3 hours. The average rating of pain intensity is ' 1.12 ' on visual analog scale for the maximum analgesic effect felt at $3^{\text {rd }}$ hour and with the first dose the analgesic effect sustained for 6 hours. The analgesic effect of tramadol has been increased for every six hours and at the end of the 24 hours, the patients scored the pain intensity of ' 2.12 ' on visual analog scale.
The analgesic effect for group ' $\mathrm{B}$ ' who were taken ketorolac started within 30 mins and showed its's maximum analgesic effect in $1^{\text {st }}$ hour itself. The pain intensity scored on visual analog is 2.45 at $1^{\text {st }}$ hour. But the effect was not sustained till the next dose. The patients felt the pain in the $5^{\text {th }}$ hour itself. The patients scored '6.94' in $5^{\text {th }}$ hour and '7.34' in $6^{\text {th }}$ hour on visual analog scale. After the second dose, the pain intensity was observed for every $6 \mathrm{hrs}$. At the end of 24 hours, the patient scored '2.98' on visual analog scale. The ' $p$ ' values were less than 0.05 and were considered statistically significant (Table 1).

According the observations, the analgesic effect is reached quickly in group ' $\mathrm{B}$ ' who received ketorolac. However, the duration of analgesia is more in group 'A' patients who received tramadol (Figure 1). Many patients in group who received ketorolac complained of pain before the dosing schedule time i.e. 6 hours.

The adverse effects in group ' $\mathrm{A}$ ' who took tramadol were minimum and they were shown only in $8 \%$ of the patients. Major adverse effects seen in this group are sweating (8\%), sedation (5\%) and decrease in blood pressure (4\%). But in group 'B' who were on ketorolac, adverse effects were observed in $33 \%$ patients. $33 \%$ patients reported the bleeding at the extraction site and $20 \%$ patients reported the epigastric pain. The intensity of adverse effects here increased as dose increased. With the first dose of ketorolac, only $8 \%$ patients reported both epigastric pain and the bleeding at the extraction site. (Table 2)

\section{Discussion}

Inspite of the spectacular advances in modern medicine, no single drug satisfied all the criteria of an ideal post extraction analgesic. Post extraction analgesia can increase the patients comfort, decrease 
the pain and stress after tooth extraction. The present study was designed to assess and compare the efficacy, safety and the patient satisfaction of two most commonly clinically used analgesics tramadol and ketorolac. Tramadol is a newer opioid with better analgesic action without the risk of developement of tolerance and physical dependence. Now it has been using very commonly for chronic pain. From the literature it has been considered as safest postoperative analgesic. ${ }^{5,12}$ Ketorolac is a most commonly used NSAID for the short term management of pain. Main focus was on the study of pain intensity and the adverse effects of both the commonly used analgesics, tramadol and ketorolac. Safety of therapy was based on the frequency of side effects and evolution of vital signs recorded during the study. From the current study it has been proved that both the drugs are giving better analgesic effect. Ketorolac is showing its analgesic effect very rapidly but the action sustained only up to 4 hours (Figure 1). Where as tramadol's analgesic effect started after 1 hour and sustained for the longer time i.e. more than 6 hours (Figure 1). The patients who received ketorolac also reported severe adverse effects like epigastric pain, bleeding at the tooth extraction site, nausea and sweating. Tramadol had a bit marked effect on blood pressure and also caused sweating in few patients (Figure 2(a), 2(b), 2(c), 2(d).

\section{Conclusion}

The overall study profile proved that tramadol is a suitable and safe analgesic with longer duration of action and less adverse effects for relief of postextraction pain after third molar extraction and is more effective than ketorolac with a long sustained analgesic action. The percentage of side effects was minimal.

\section{References}

1. Oladimeji A Akadiri, Ambrose E Obiechina.: Assessment of difficulty in third molar surgery-a systematic review. Oral Maxillofac Surg. 2009 (Apr); 67 (4):771-4.

2. Capuzzi P ontebugnoli L M Vaccaro MA.: Extraction of impacted third molars. A longitudinal prospective study on factors that affect postoperative recovery. Oral Surg Oral Med Oral Pathol. 1994 (Apr).; 77 (4) : 341-3.

3. HUSSAIN AL-KHATEEB Taiseer; ALNAHAR Amir.: Pain Experience After Simple Tooth Extraction, Journal of oral and maxillofacial surgery. 2008 (May).; (66), 911-7

4. De Beer Jde V, Winemaker MJ, Donnelly GA, et al.: Efficacy and safety of controlled-release oxycodone and standard therapies for postoperative pain after knee or hip replacement. Can J Surg. 2005; 48:277.

5. Recart A, Duchene D, White PF, et al.: Efficacyand safety of fast-track recovery strategy for patients undergoing laparoscopic nephrectomy. J Endourol 2005; 19:1165.

6. Watcha MF, Issioui T, Klein KW, et al.: Costs and effect of rofecoxib, celecoxib, and otolaryngologic surgery. Anesth Analog.; 2003; 96: 987

7. Pozos-Guillén Ade J, Martínez-Rider R, AguirreBañuelos P, et al.: Analgesic efficacy of tramadol by route of administration in a clinical model of pain. Proc West Pharmacol Soc. 2005; 48: 61-4.

8. Zackova M, Taddei S, Calò P, et al.: Ketorolac vs tramadol in the treatment of postoperative pain during maxillofacial surgery. Minerva Anestesiol. 2001 (Sep);67(9):641-6. 
M M Shaik et al. Comparative study of Tramadol and Ketorolac in the pain management of third molar tooth extraction

9. Ong KS, Tan JM.:Preoperative intravenous tramadol versus ketorolac for preventing postoperative pain after third molar surgery. Int J Oral Maxillofac Surg. 2004(Apr);33(3):274-8.

10. Melzack R.:The Mc Gill Pain Questionnaire: Major properties and scoring methods. 1975;277-99
11. Seymour RA.:The use of pain scales in assessing the efficacy of analgesics in post-operative dental pain Eur J Clin Pharmacol. 1982;23(5):441-4.

12. Stamer Um, Maier C, Grond S, Veh-Schmidt, Klaschik E, Lehman KA.: Tramadol in the management of postoperative pain: a double-blind, placebo-and active drug-controlled study. Eur J Ana. 1997;12(6):646-54.

Table 1: Comparison of Pain intensities of Tramadol and Penatazocine

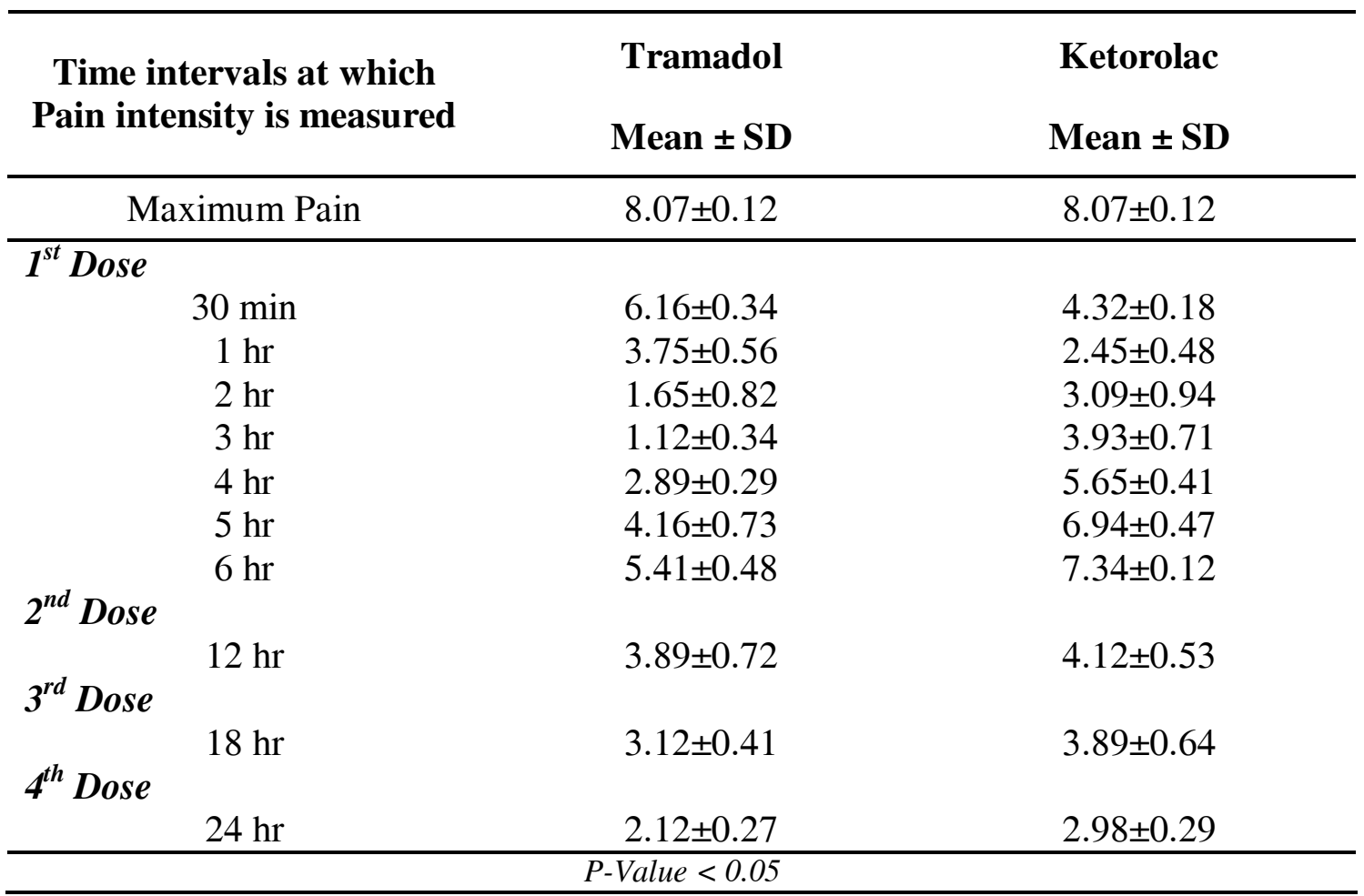


Figure 1: Graphical representation - Comparison of pain intensities of Tramadol and Ketorolac

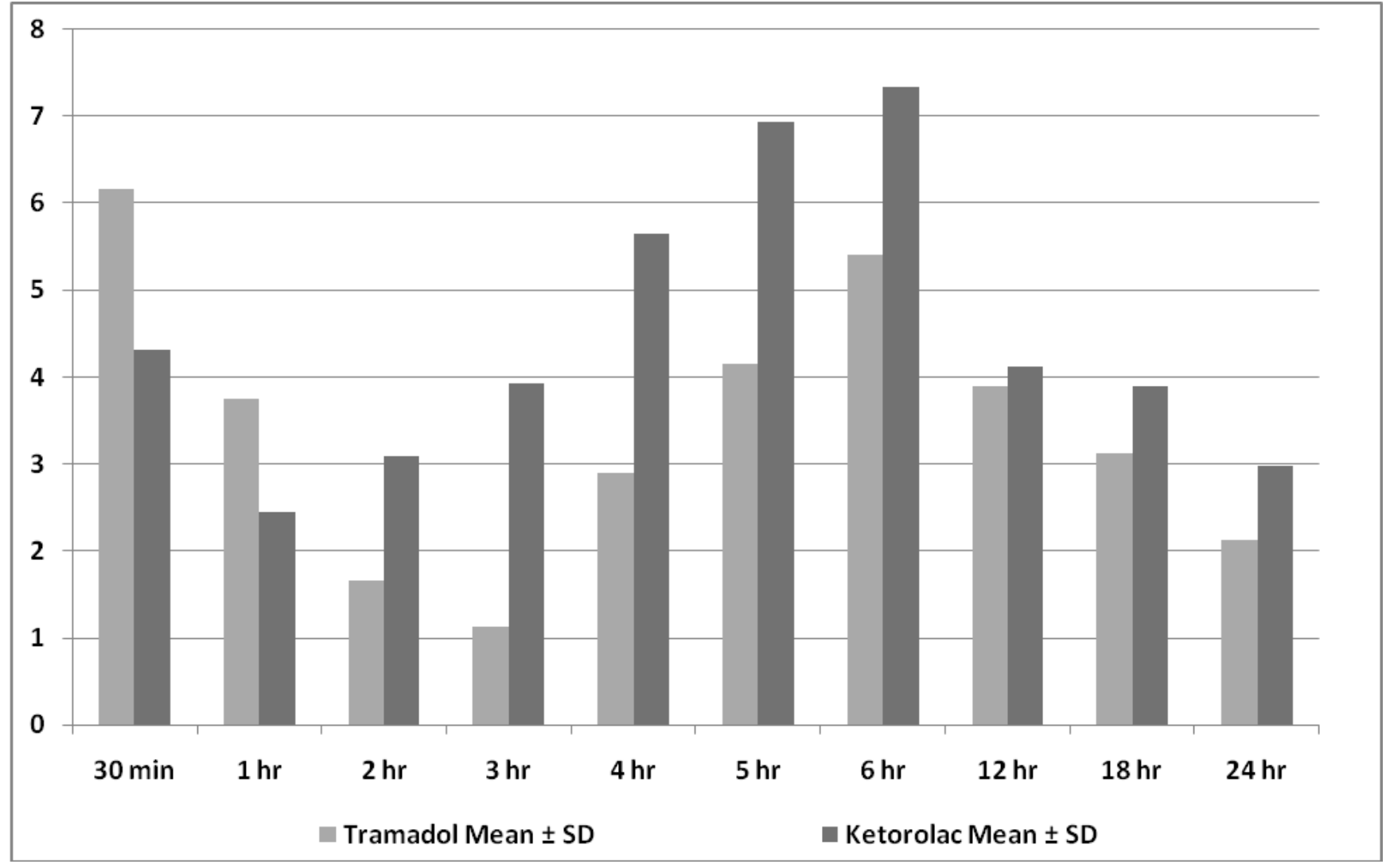


Table 2: Side effects distribution of Tramadol and Pentazocine

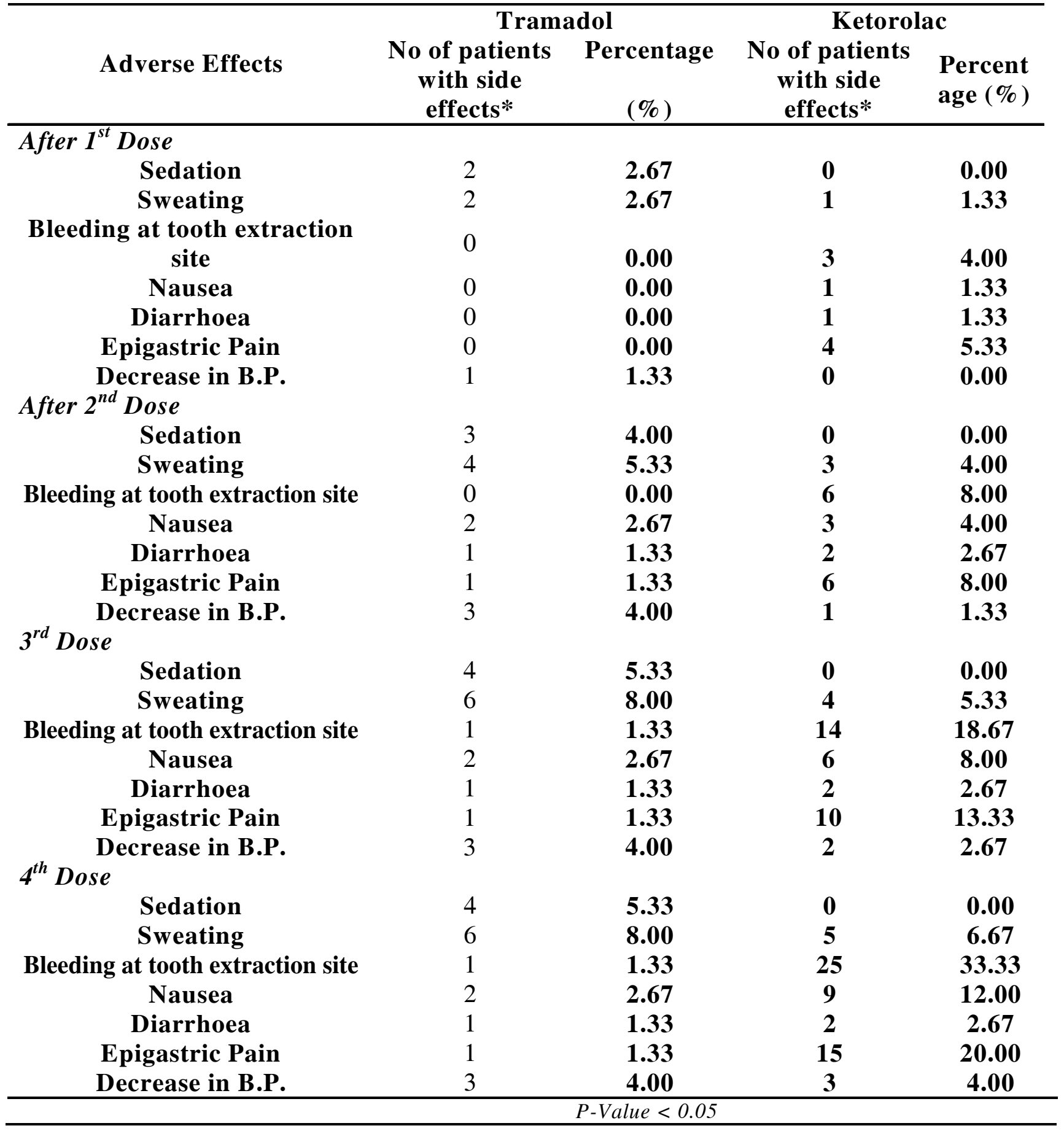

* Each group contains total number of 75 patients 
Journal of College of Medical Sciences-Nepal, 2010, Vol. 6, No. 1

Figure 2(a): Graphical representation - Comparison of Adverse effects of Tramadol and Ketorolac after $1^{\text {st }}$ dose

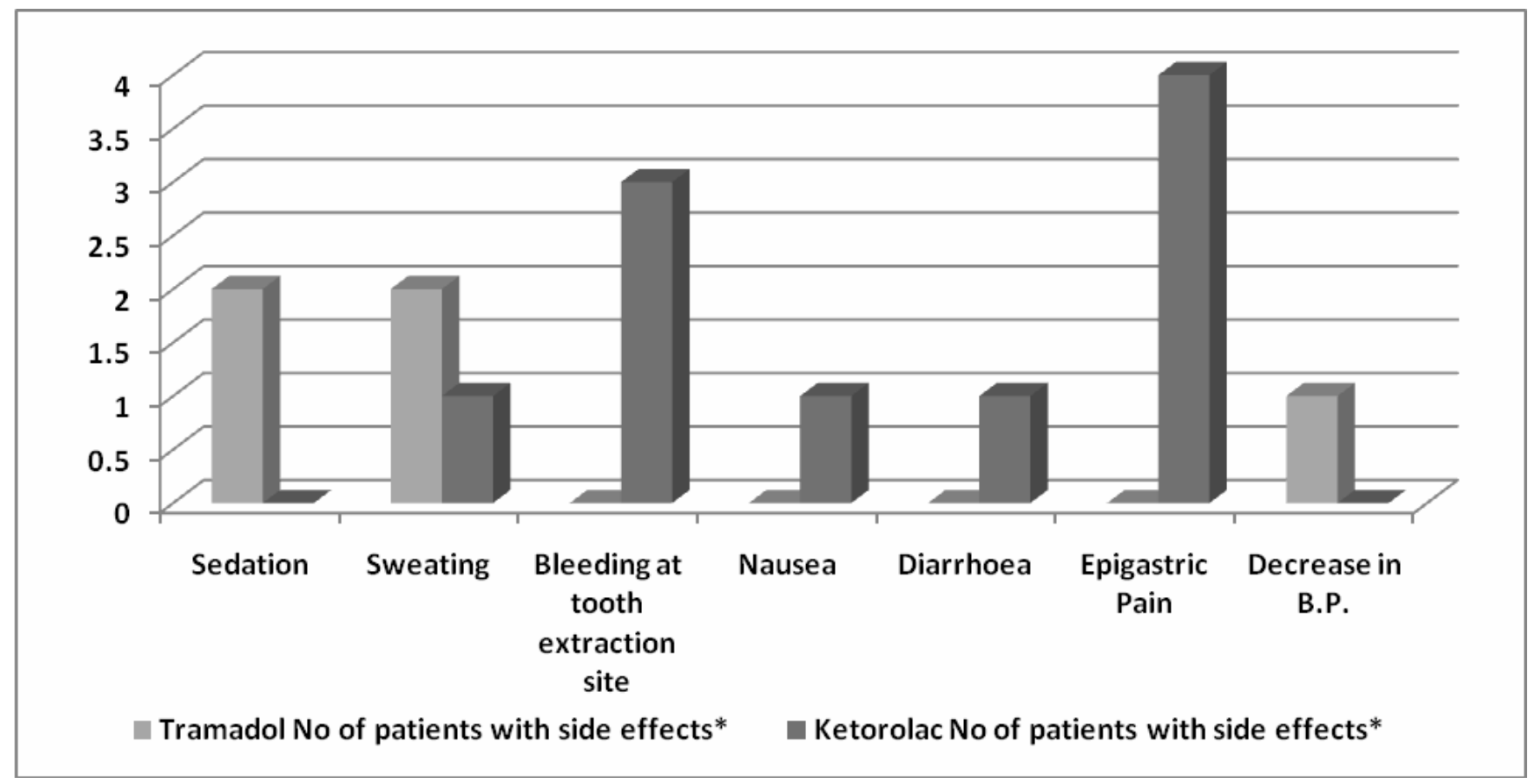

Figure 2(b): Graphical representation - Comparison of Adverse effects of Tramadol and Ketorolac after $2^{\text {nd }}$ dose

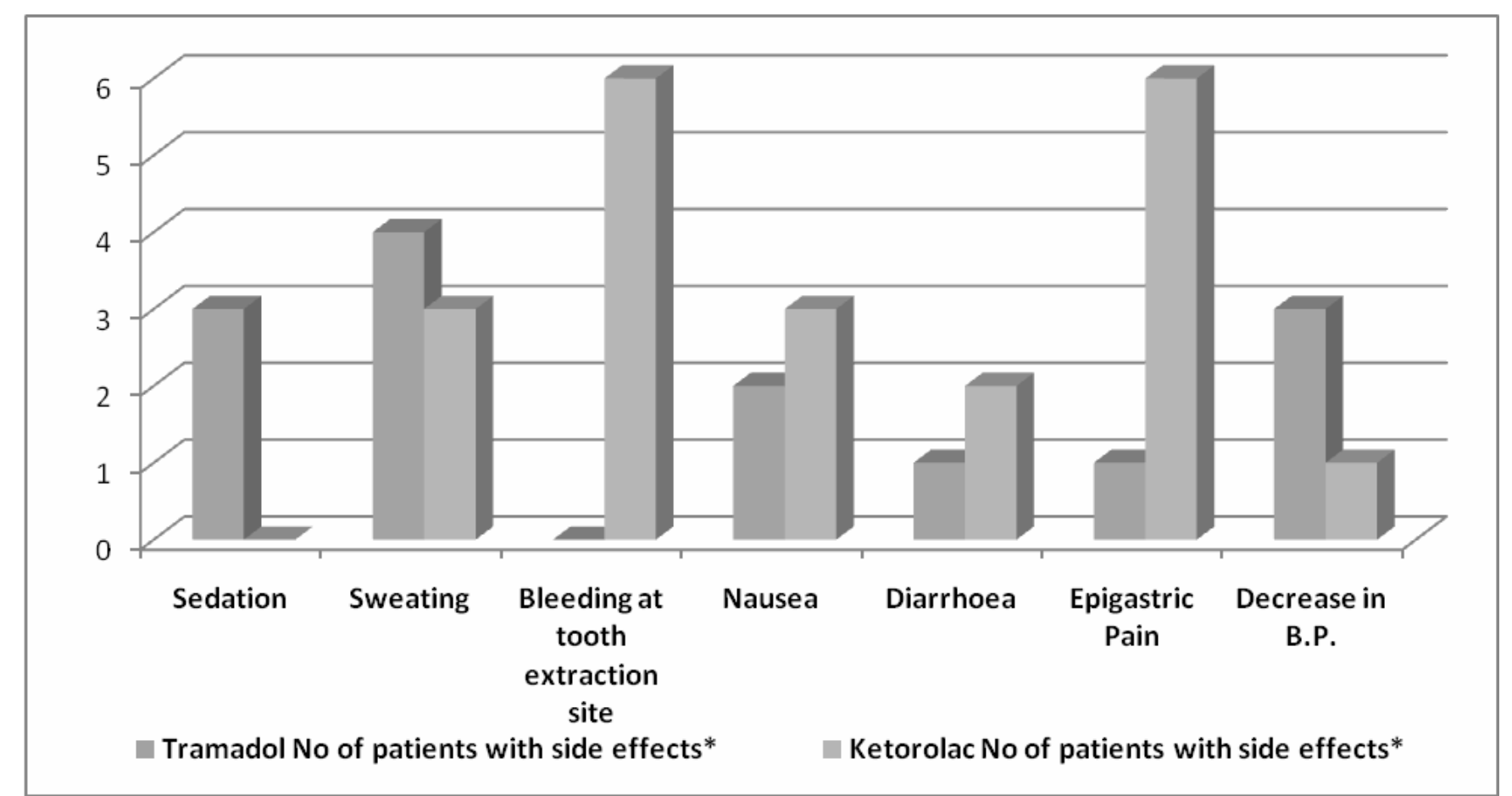




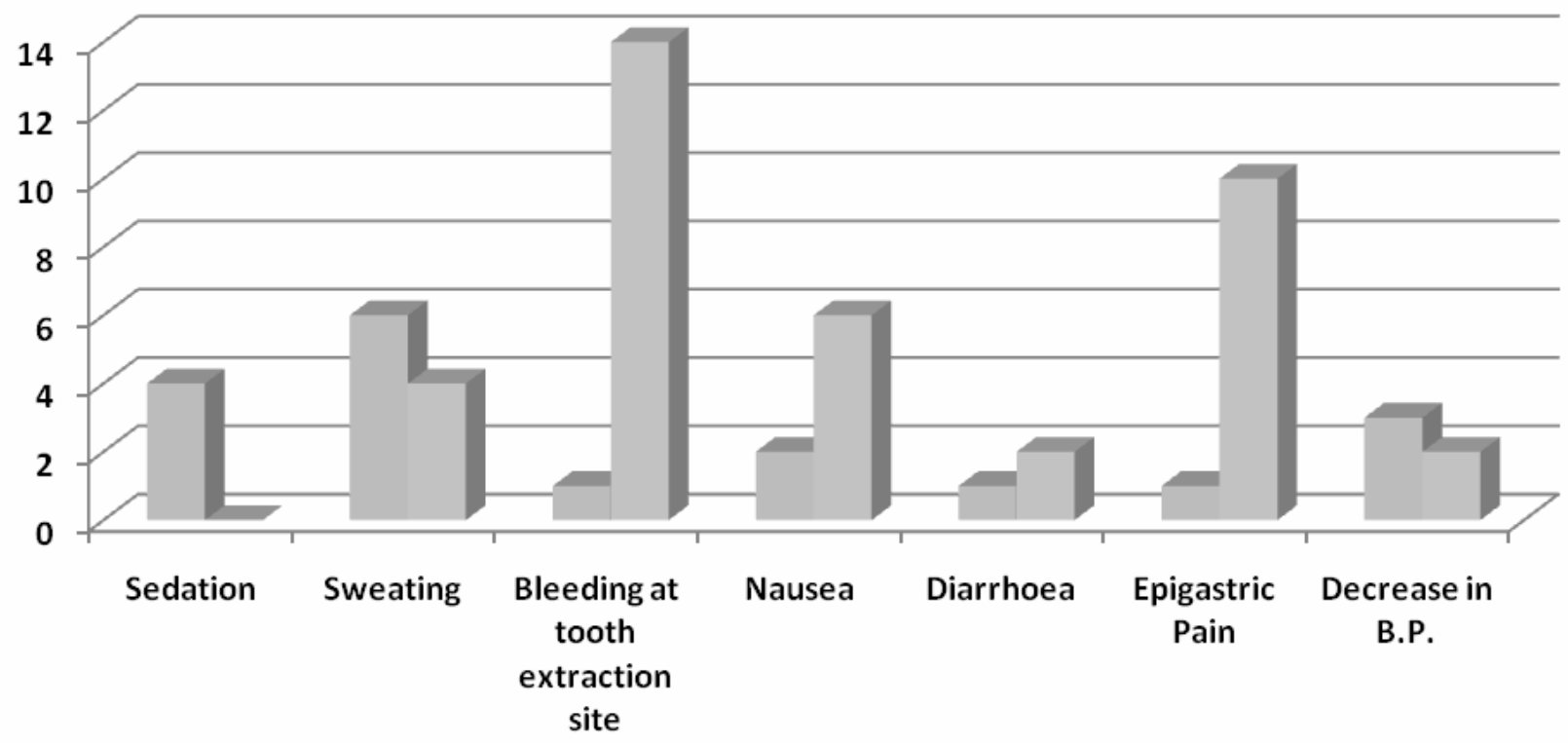

Tramadol No of patients with side effects* Ketorolac No of patients with side effects*

Figure 2(d): Graphical representation - Comparison of Adverse effects of Tramadol and Ketorolac after $4^{\text {th }}$ dose

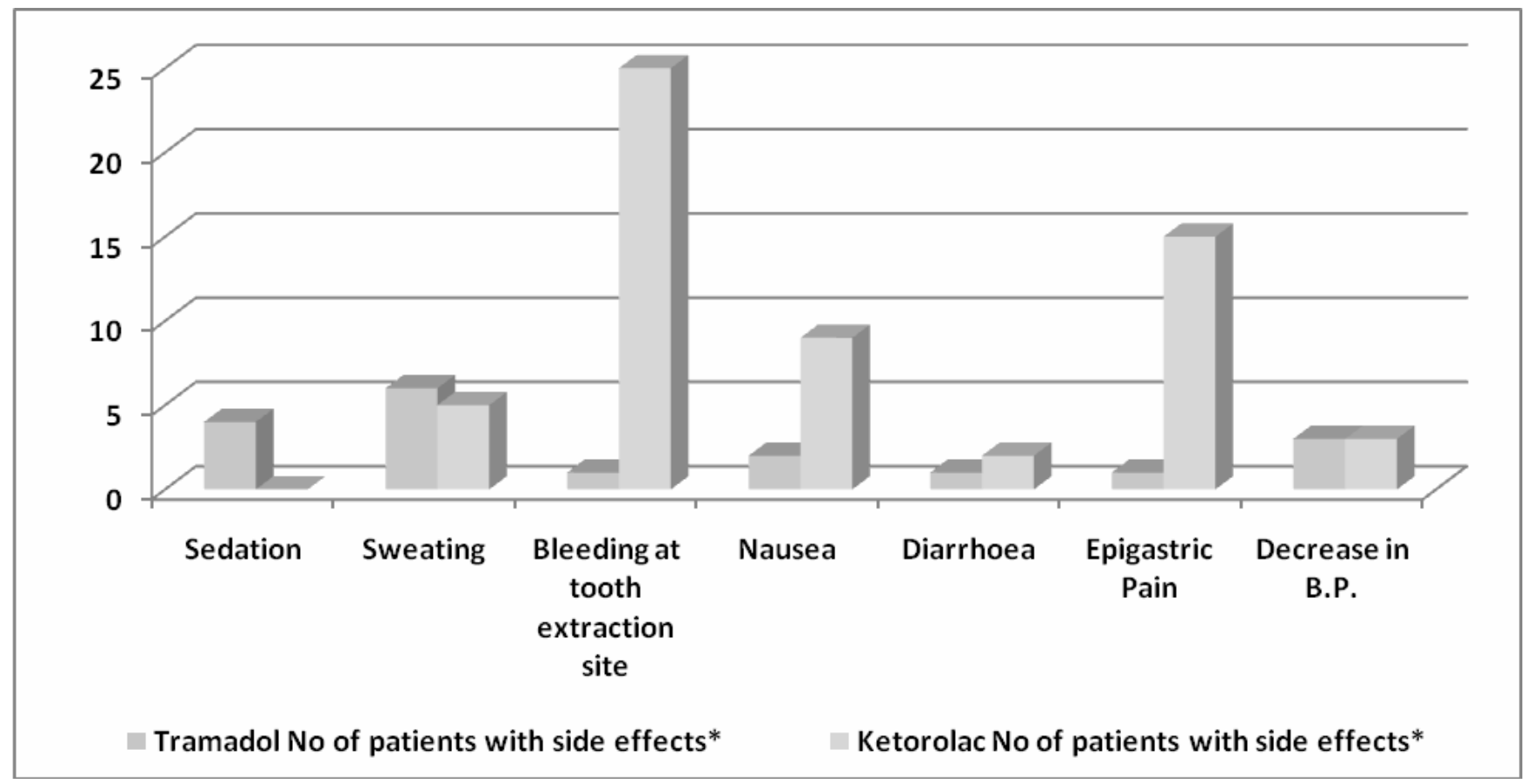

